UOT 547.425:547.464:547.569

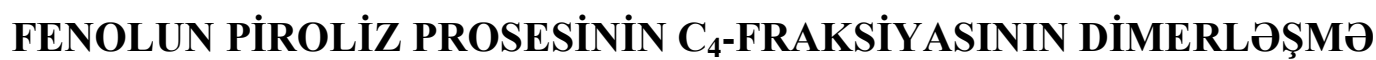 MOHSULLARI ILO ALKILLOŞMO REAKSIYYASININ BəZI XÜSUSIYYYTLӘRİ
}

\author{
V.H.Mirzəyev \\ AMEA Y.Mammadaliyev adina Neft-Kimya Proseslari Institutu \\ Az1025 Bakl, Xocalı prospekti, 30; e-mail: Tural110@mail.ru
}

Fenolun KУ-23 katalizatoru iştirakında aşağı oktanlı benzinlərin pirolizi prosesində alınan divinilsizlaşdirilmişs $C_{4}$-fraksiyasının dimerlaşmə mahsulları ila alkillaşma reaksiyası tədqiq olunmuşdur. Alkillaşmə reaksiyası fasilali qurğuda həyata keçirilmişdir. Reaksiya nəticəsində maqsadli mahsulun çıxımına va seçiciliyina temperaturun, vaxtın, ilkin komponentlarin mol nisbətlorinin vo katalizatorun miqdarının tasiri araşdırılmışdır.Tadqiqat nəticəsində müəyyən edilmişdir ki, fenolun piroliz prosesinin $C_{4}$-fraksiyasının dimerlaşma məhsulları ila $K Y-23$ katalizatoru iştirakında alkilləşmə reaksiyasının aşağıda göstərilon şəraitində: temperatur $120^{\circ} \mathrm{C}$, fenolun fraksiyaya 1:2 mol nisbatindo, vaxtın 5 saat, katalizatorun miqdarının 10\% qiymatindo maqsadli məhsulun çıxımı götürülan fenola göra $80.4 \%$, seçicilik isa maqsadli məhsula göra $95.7 \%$ olur.

Açar sözlor: fenol, $C_{4}$-fraksiyasının dimerlaşmə məhsulları, alkillaşmə, n-alkilfenol

\section{GíRiş}

Polimer materiallara, yağlara və yanacaqlara əlavə olunan antioksidantlar, aşqarlar, stabilizatorlar və s.kimyəvi əlavələr içərisində alkilfenollar əsasında alınmış kimyəvi birləş-mələr xüsusi yer tutur. Onlar poliolefinlərin rəngini dəyişmir, yüksək temperatura davamlıdırlar, yağlarda və yanacaqlarda yaxşı həll olurlar [1-6].

Hazırda sənayedə istifadə olunan alkilfenolların oksəriyyəti fenolun polimerdistillat ilə alkilləşməsindən alınır. Son vaxtlar polimerdistillatın istifadəsi başqa səmtə

yönəldiyindən (polimerdistillat destruksiyaya uğradılaraq benzinə komponent kimi istifadə olunur) fenolun alkilləşmə reaksiyaları sahəsində alkilləşdirici agent q1tlı̆̆ yaranmışdır.

Təqdim olunan məqalədə fenolun KУ-23 katalizatoru iştirakında aşağ 1 oktanlı benzinlərin pirolizi prosesində alınan divinilsizləşdirilmiş $\quad \mathrm{C}_{4}$-fraksiyasının dimerləşmə məhsul-larının $\quad 105-190^{\circ} \mathrm{C}$ farksiyası (IDF) ilə alkilləşmə reaksiyalarının tədqiqindən bəhs edilir.

\section{TəCRÜBİ HISSSə}

Təcrübələrin aparılması üçün ilkin xammal kimi qabaqcadan qovulmuş fenoldan və IDF-dan istifadə edilmişdir. Alkilləşdirici agent kimi aşağı oktanlı benzinin pirolizi prosesində alınan divinilsizləşdirilmiş $\mathrm{C}_{4}{ }^{-}$ fraksiyasından (BİF) istifadə edilmişdir. BİFnın seolit katalizatoru üzərində dimerləşməsindən 40.5\% izobutilenin oliqomerləri

İlkin xammalda izobutilenin dimerinin və trimerinin qatılığını artırmaq məqsədilə alkilləşmə reaksiyaları üçün izobutilenın oliqomerlərinin $105-190^{\circ} \mathrm{C}$ fraksiyasından istifadə edilmișdir. BİF-nın dimerləşmə məhsullarının və İDF-nın karbohidrogen tərkibləri 1 saylı cədvəldə verilir.

Cədvəl 1.BİF-nın dimerləşmə məhsullarının və İDF-nın karbohidrogen tərkibi

\begin{tabular}{|l|c|c|}
\hline \multicolumn{1}{|c|}{ Karbohidrogenlər } & BİF-1n dimerləşmə məhsulları, $\%$ & $105-190^{\circ} \mathrm{C}$ frak. \\
\hline $\mathrm{C}_{5}-\mathrm{C}_{7}$ & 1.07 & 0.68 \\
İzooktan & 0.15 & 0.54 \\
Diizobutilen & 38.78 & 51.35 \\
Diizobutilenin izomeri & 21.09 & 27.60 \\
\hline
\end{tabular}




\begin{tabular}{|l|c|c|}
\hline Trimerlər & 32.76 & 19.83 \\
Tetramerlər və yuxarı & 6.17 & - \\
\hline
\end{tabular}

1 saylı cədvəldən görünür ki, BİF-nın dimerləşmə məhsullarının $105-190^{\circ} \mathrm{C}$ fraksiyasının karbohidrogen tərkibində 51.32\%-ə qədər diizobutilen var, deməli fenolun İDF ilə alkilləşmə reaksiyasının əsas məhsulu paraüçlüoktilfenol olacaqdır.

IDF-nın fiziki-kimyəvi göstəriciləri: qayn.temp. $105-190^{\circ} \mathrm{C} ; \quad \mathrm{n}_{\mathrm{D}}{ }^{20} 1.4473 ; \quad \rho_{4}{ }^{20}$ 0.8167-mol.k.120.

Alkilləşmə reaksiyası üçün katalizator kimi kationit KУ-23 (DÜST 20298-74) istifadə olunmuşdur.

KY-23 (modifikasiya 10/60) tərkibində 55-70\%-dək su saxlayır, $170^{\circ} \mathrm{C}$-dək termiki sta-bildir. Ona görə KУ-23 istifadədən qabaq sudan azad olmaq üçün $110^{\circ} \mathrm{C}$-dək q1zdırılır. İş prosesində temperaturun təsiri ilə katalizatordan sulfoqrupun ayrilması və onun üzərinə qətranabənzər maddələrin toplanması nəticəsində katalizatorun fəallığı aşağı düşür. $\mathrm{KY}-2$ katalizatorundan fərqli olaraq $\mathrm{KУ}-23$ katalizatorunu 2-4\%-li xlorid turşusu ilo regenerasiya edərək yenidən istifadə etmək olur.

Fenolun İDF ilə alkilləşmə reaksiyası üç boğazlı kolbada həyata keçirilmişdir. Alınmış alkilat Klayzen kolbasına keçirilərək rektifikasiya olunmuşdur. Rektifikasiya nəticəsində ilk öncə reaksiyaya girməyən IDF və fenol $\left(200^{\circ} \mathrm{C}\right.$-dək), sonra isə aşağ ${ }_{1}$ təzyiqdə (5 mm.c.st.) məqsədli məhsul və digər alkilləşmə məhsulları ayrılır. Alınmış məhsulların fiziki-kimyəvi xassələri, kimyəvi quruluşları və tərkibləri təyin edilir.

Reaksiya və rektifikasiya məhsullarının xromatoqrafik analizi LXM-72 xromatoqrafinda həyata keçirilmişdir. Kalonun uzunluğu $2 \mathrm{~m}$, bərk daşıyıcı kimi turşu ilə yuyulub dimetilxlorsilanla silanlaşdırılmış $0.2 \pm 0.25$ mm ölçüdə xromaton N-AW-DMC, hərəkətsiz faza kimi 5\%-li SE-30 metilsiloksan elastomeri götürülmüşdür. Kalonun ilkin temperaturu $50^{\circ} \mathrm{C}$, son temperaturu $280^{\circ} \mathrm{C}$, proqramlaşmanın sürəti $10^{\circ} \mathrm{C} / \mathrm{dəq}$, helium qazının sürəti $50 \mathrm{ml} / \mathrm{dəq}$, buxarlandırıcının temperaturu $250^{\circ} \mathrm{C}$, detektorun temperaturu $300^{\circ} \mathrm{C}$, diaqram lentinin sürəti $60 \mathrm{~mm} / \mathrm{saat}$.

Sintez olunmuş mohsulların sıxlığı piknometrik üsulla, şüasındırma əmsalları «ИРФ-22» (Rusiya) refraktometrik üsulla təyin edilmişdir.

Reaksiya məhsullarının spektrləri Almaniyanın "BRUKER" firmasının ALPHA İQ-Furye spektrometrində $\mathrm{Se} / \mathrm{Zn}$ kristalı üzərində, dalğa uzunluğu 600-4000 sm $\mathrm{sm}^{-1}$ diapazonunda çəkilmişdir. H'MR spektrləri "Bruker" firmasının (Almaniya) Furye spektrometrində $300.18 \mathrm{MHs}$ iş tezliyində, otaq temperaturunda deyteriumlaşmış benzol məhlulunda çəkilmişdir. Siqnalların (m.h.) kimyəvi sürüşmələri tetrametilsilana nisbətən götürülmüşdür. Müxtəlif struktur fraqmentlərin protonlarının nisbi tərkibləri spektrlərin müvafiq zolaqlarındakı piklərin sahələrini inteqrallaşdırmaqla təyin edilir.

\section{NOTÍCOLӘRIN MÜZAKİRəSI}

Fenolun IDF ilə KY-23 katalizatoru iştirakında alkilləşmə reaksiyası aşağıdakı sxem üzrə gedir.

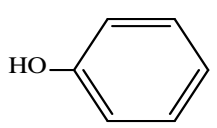

Para-alkilfenolun alınmasının səmərəli şəraitini tapmaq üçün reaksiyanın temperaturunun, vaxtının ilkin komponentlərin mol nisbətlərinin və katalizatorun miqdarının məqsədli məhsulun çıxımına və seçiciliyinə təsiri araşdırılmışdır.

Alkilləmə reaksiyasının temperaturu 60dən $140^{\circ} \mathrm{C}$-dək, reaksiyanın müddəti 2-6 saat, fenolun İDF-na mol nisbəti 2:1-dən 1:2-dək, katalizatorun miqdarı 5-20\% hədlərində tədqiq olunmuşdur.

Fenolun KУ-23 katalizatoru iştirakında IDF ilə alkilləşmə reaksiyalarının nəticələri 2 saylı cədvəldə verilir.

Cədvəl 2-dən görünür ki, reaksiyanın temperaturunun 60 -dən $120^{\circ} \mathrm{C}$-dək artırılmas 1 
ilə ç1xım 39.3-dən 80.4\%-dək (götürülən fenola görə), reaksiyanın seçiciliyi isə məqsədli məhsula görə 87.8-95.7\% həddində dəyişir. Temperaturun $140^{\circ} \mathrm{C}$-dək artırılması ilə məqsədli məhsulun müvafiq olaraq çıxımı 73.9\%, seçicilik isə $87.0 \%$ hədlərində olur.

Cədvəlin göstəricilərindən məlum olur ki, komponentlər qarışığında fenolun İDF-na mol nisbətinin 1:2 götürülməsi daha məqsədəuyğundur. Belə ki, bu zaman məqsədli məhsulun çıxımı $80.4 \%$, seçicilik isə $95.7 \%$ olur. İlkin komponentlər qarışı̆̆ında fenolun və ya İDF-nın qatılı̆̆ının artırılıb azalması ilə məqsədli məhsulun çıxımındə və reaksiyanın seçiciliyində elə bir ciddi nəticəyə nail olmaq olmur. İDF-nın qatlığını 3-4 dəfə artırmaqla məqsədli məhsulun çıxımı 2-2.5\% artmış olur. Lakin bu həm texnoloji, həm də iqtisadi baxımdan sərfəli deyil. Bu zaman seçiciliyin xeyli aşağı düşməsi müşahidə olunur; bu alkilləşmə reaksiyası nəticəsində 2mono, 2,4-, 2,6-di və 2,4,6-üç-əvəzlənmiş alkilfenolların alınması ilə izah olunur:

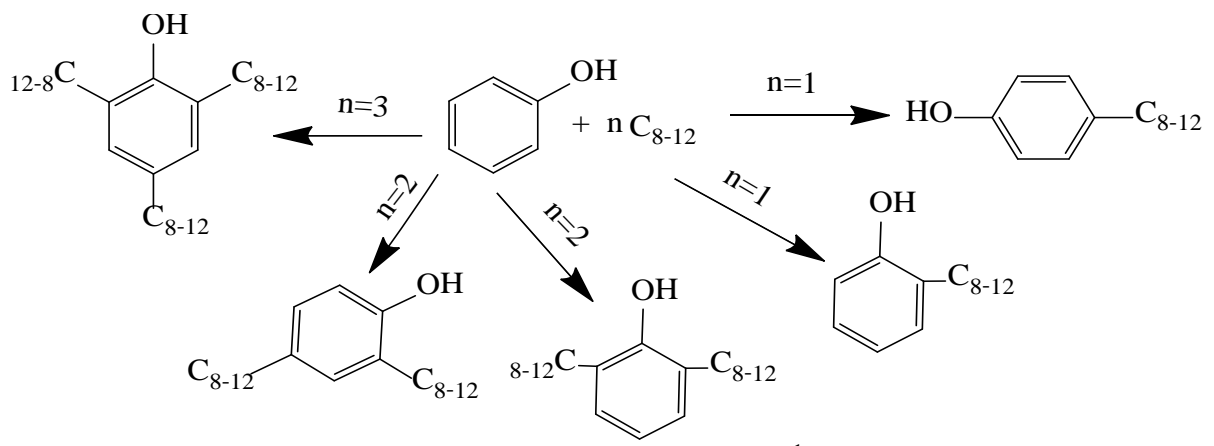

İlkin komponentlər qarışığının katalizator ilə görüşmə müddətinin məqsədli məhsulun çıxımına və reaksiyanın seçiciliyinə təsiri də önəmlidir. 2 saylı cədvəldən görünür ki, reaksiya müddətinin 5 saat qiymətində məqsədli məhsulun çıxımı $80.4 \%$, seçicilik isə 95.7\% Katalizatorun $10 \%$ miqdarında məqsədli məhsulun səmərəli çıxımına və seçiciliyinə nail olmaq olur. Katalizatorun 15$20 \%$ qiymətlərində isə çı1m $81.7-83.0 \%$, seçicilik isə müvafiq olaraq 95.2-88.3\% olur. $\mathrm{Bu}$ zaman çıxım cüzi artsa da, secicilik aşağı düşür.

Beləliklə, fenolun KУ-23 katalizatoru iştirakında IDF ilə alkilləşmə reaksiyası üçün səmərəli şərait tapılmışdır: temperatur $120^{\circ} \mathrm{C}$, reaksiyanın müddəti 5 saat, fenolun IDF-na mol nisbəti 1:2, katalizatorun miqdar1 - 10\%. $\mathrm{Bu}$ şəraitdə para-alkil( $\left(\mathrm{C}_{8-12}\right)$-fenolun götürülən fenola görə çıxımı $80.4 \%$, seçiciliyi isə məqsədli məhsula görə $95.7 \%$ təşkil edir. Sintez olunmuş p-alkilfenolun kimyəvi quruluşu $\mathrm{H}^{1} \mathrm{NMR}$ və İQ spektroskopik üsullarla təyin edilmişdir.

P-alkilfenolun $\mathrm{H}^{1} \mathrm{NMR}$ spektrində sinqlet $\mathrm{CH}_{3}$ qrupu 1.20 ppm, karbohidrogen həl-qəsinin yayılmış sinqleti 1.77 ppm, OHqrupu və multiplet 1.4 əvəzlənmiş benzol həlqəsi 5-6 ppm zolağında müşahidə olunmuşdur.

P-alkilfenolun İQ spektrində aşağıdak1 zolaqlar müşahidə olunmuşdur: $1505,1592-$ $1610 \mathrm{sm}^{-1}$ (benzol həlqəsi), 3010, $3030 \mathrm{sm}^{-1}$ $\mathrm{CH}_{2}=$ valent sürüşməsi), $825 \mathrm{sm}^{-1}$ $\left(\mathrm{CH}_{2}=\right.$ deformasiya sürüşməsi);

OH-qrupu $1240 \mathrm{sm}^{-1}$ və $3100-3500 \mathrm{sm}^{-1}$ zolaqlarında müşahidə olunur. Hem-əvəzolunmuş üçlü karbonun varlığ $\mathrm{C}-\mathrm{H}$ valent sürüşmələri 2920-2845 sm $\mathrm{sm}^{-1}$ zolaqlarında, eyni zamanda $\delta_{\mathrm{CH} 2}$ xarakterizə edən 1108, $1345 \mathrm{sm}^{-}$ 1 zolaqlarında müşahido olunur. Metil qrupları 1370 və $1460 \mathrm{sm}^{-1}$ deformasiya sürüşmələri ilə xarakterizə olunur. Para-alkil( $\left(\mathrm{C}_{8-12}\right)$-fenolun fiziki-kimyəvi xassələri 3 saylı cədvəldə verilir 


\begin{tabular}{|c|c|c|c|c|c|c|c|c|c|c|c|c|c|c|c|c|c|}
\hline 罻 & & $\left|\begin{array}{l}\infty \\
\infty \\
\infty\end{array}\right|$ & & & & & 2 & ڤ. & ఖ & & & & & & & & \\
\hline 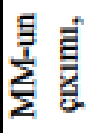 & & ले & 官 & & : & $\hat{\infty}$ & $\frac{0}{6}$ & : & $\vec{F}$ & & :े & है: & & 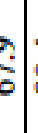 & & $\left.\frac{1}{\infty}\right|_{2}$ & \\
\hline & $\underline{\underline{x}}$ & $\stackrel{-1}{-}$ & 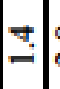 & & तี & $=$ & กี & ปู & ले & $\infty$ & กี & ○े & & & & $\stackrel{0}{\mathrm{i}}$ & \\
\hline & 蒠 & $\mid \begin{array}{l}\infty \\
\vdots \\
0 \\
0\end{array}$ & $\begin{array}{l}0 \\
\vdots \\
\vdots \\
-1\end{array} \mid$ & 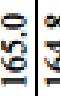 & \begin{tabular}{l}
$\infty$ \\
\multirow{3}{*}{}
\end{tabular} & 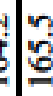 & $\begin{array}{l}\infty \\
\mathbb{0} \\
0\end{array}$ & $\begin{array}{l}\infty \\
\underline{\tilde{t}} \\
-\end{array}$ & 울 & 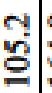 & \begin{tabular}{l}
$\infty$ \\
\multirow{3}{0}{}
\end{tabular} & $\vec{\Delta}$ & & & है & : & \\
\hline & 吾 & $\stackrel{n}{\mathrm{i}}$ & is & $m$ & & $\approx$ & 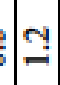 & $\because$ & $=$ & $m$ & $?$ & 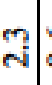 & & $=$ & & $\int_{r}^{r}$ & \\
\hline$\hat{\xi}$ & $\sum$ & लि & $\mid \begin{array}{c}\text { N1 } \\
\text { mat }\end{array}$ & 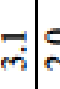 & î & 8 & $?$ & î & के & 일. & 이 & $\vec{i}$ & 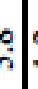 & & & $y$ & \\
\hline$\frac{\text { 恶 }}{<}$ & $\sum$ & $\mid \overrightarrow{\mathrm{i}}$ & : & $\frac{1}{20}$ & : & 8 & ชุ & $\mid \begin{array}{l}0 \\
\\
\end{array}$ & ని & $\overline{6}$ & $\stackrel{8}{\circ}$ & $\bar{\infty}$ & & & & $\left.\right|_{\alpha} ^{\alpha}$ & \\
\hline & 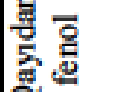 & 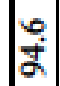 & $\infty$ & & & & : & مి & 官 & $\begin{array}{l}\infty \\
\Xi\end{array}$ & :ํ. & సี|: & 6 & & & & \\
\hline & 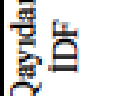 & तें & ลิ & 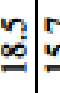 & $=$ & ते & 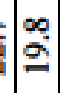 & $\underline{\sim}$ & $=$ & 어 & $\stackrel{\text { ڤே }}{2}$ & $\vec{\infty}$ & $?$ & & & $=$ & \\
\hline 菷 & 番 & 으 & 의 & 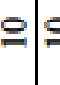 & 의옹 & 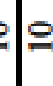 & 으 & 으 & 의 & 으 & 의 & 으 & & & $e$ & 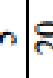 & \\
\hline 焉 & 可 & 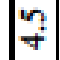 & $?$ & $\stackrel{n}{*}$ & $\because$ & $N$ & $m$ & $?$ & 0 & $\stackrel{n}{q}$ & $?$ & $?$ & & $?$ & & $=$ & 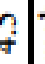 \\
\hline$\approx$ & 鄫。 & 8 & 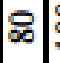 & ఏీఏ & 길. & 요 & 얼 & సิ & 이 & తి & 오 & తి & & & & & \\
\hline 㖟 & 峘 & 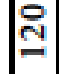 & 고. & 요 & 워 & 글 & 워 & בิ & ఫิ & 8 & సิ & 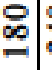 & P & $\underline{Z}$ & 기 & & \\
\hline 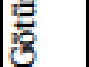 & 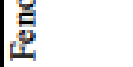 & $q$ & Fl: & $\approx 9$ & 8 & $F$ & 7 & ₹ & F & 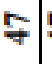 & 于 & $f:$ & + & 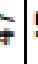 & t & $\Rightarrow$ & 4 \\
\hline 象 & & - & & 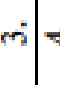 & $\dot{8}^{\circ} 1 \mathrm{v}$ & $0^{\circ}$ & $1 n$ & $\infty$ & & 음 & $=$ & & & & & $=$ & \\
\hline
\end{tabular}


Cədvəl 3. Para-alkil( $\left.\mathrm{C}_{8-12}\right)$-fenolun fiziki-kimyəvi xassələri

\begin{tabular}{|c|c|c|c|c|}
\hline Struktur formula & $\begin{array}{c}\mathrm{T}_{\text {qayn. }}{ }^{\circ} \mathrm{C} / \\
5 \mathrm{~mm} \text { c.st. }\end{array}$ & $\mathrm{n}_{\mathrm{D}}{ }^{20}$ & $\rho_{4}{ }^{40}$ & Mol. kütlə \\
\hline & $140-160$ & 1.5445 & $\begin{array}{c}1.004 \\
0\end{array}$ & 280 \\
\hline $\mathrm{C}_{8 \cdot 12}$ & & & 0 \\
\hline
\end{tabular}

\section{NəTİCə}

Fenolun KУ-23 katalizatoru iştirakında İDF ilə alkilləşmə reaksiyaları tədqiq olunmuşdur. Müəyyən edilmişdir ki, reaksiyanın optimal şəraitində- $120^{\circ} \mathrm{C}$ temperaturda, reaksiya vaxtının 5 saat, fenolun İDF-ə 1:2 mol nisbətində, katalizatorun 10\% qiymətlərində para-alkil( $\left.\mathrm{C}_{8-12}\right)$-fenolun çıxımı götürülən fenola görə $80.4 \%$, reaksiyanın seçiciliyi isə məqsədli məhsula görə $95.7 \%$ olur.

\section{ӘDӘВIYYYAT}

1. Расулов Ч.К., Азизов А.Г., Мирзоев В.Г. Каталитическое арилирование и алкилирование фенола компонентами фракции $130-170^{\circ} \mathrm{C}$ продуктов пиролиза. // Нефтехимия. 2009, т.49, № 5, с.397-400.

2. Коренев Д.К., Заворотный В.А., Келарев В.Б. Поиск катализатора алкирования фенола олефинами. // Химия и технология топлив и масел. 2003, № 1, с. 61-63.

3. Мирзоев В.Г. Каталитическое циклоалкенилирование фенола 3-винил циклогексеном на непрерывнодействующей установке. // Процессы нефтехимии и нефтепереработки. 2015, т.17, № 2, с.101-105.

4. Магеррамов А.М., Байрамов М.Р., Мехтиева Г.М., Агаева М.А. Получение аминометилированных производных аллилфенолов и исследование их антимикробных свойств в моторном масле. // Журн. прикл. химии. 2007, т.80, вып.4, с.681-686.

5. Расулов Ч.К., Азизов А.Г., Азимова Р.К., Абасов С.И. Взаимодействие фенола циклодимерами изопрена в присутствии цеолита $\mathrm{У}$, пропитанного ортофосфорной кислотой. //Нефтехимия. 2012, т.52, №1, с.1-5.

\section{REFERENCES}

1. Rasulov Ch.K., Azizov A.G., Mirzoev V.G. Catalytic arylation and alkylation of phenol by components of $130-170^{\circ} \mathrm{C}$ fraction of pyrolysis products. Neftehimiya Petroleum Chemistry. 2009, vol.49, no. 5, pp.397-400. (In Russian).

2. Korenev D.K., Zavorotnyj V.A., Kelarev V.B. Search for catalyst of phenol alkylation by olefines. Himija i tehnologija topliv i masel - Industrial Chemistry and Chemical Engineering. 2003, no. 1, pp. 61-63. (In Russian).

3. Mirzoyev V.G. Catalytic cyclo-alkylation of phenol 3-vinylcyclohexene on a continuously operating facility. Processes of Petrochemistry and Oil Refining. 2015, vol.17, no. 2, pp.101-105. (In Azerbaijan).

4. Magerramov A.M., Bajramov M.R., Mehtieva G.M., Agaeva M.A Production of amino-methylated derivatives of allilphenols and research into their anti-microbial properties in motor oil. Zhurnal Prikladnoi Khimii - The Russian Journal Of Applied Chemistry . 2007, vol. 80, no.4, pp.681-686. 
5. Rasulov Ch.K., Azizov A.G., Azimova R.K., Abasov S.I. Interaction between phenol and isoprene cyclodymers in the presence of orthophosphoric acid-impregnated zeolite Y. Neftehimiya - Petroleum Chemistry. 2012, vol.52, no. 1, pp.1-5. (In Russian).

6. Harlamova T.A., Alaferdov A.F, Maslova O.V. Influence of electrochemical impact on destruction of organic compounds. Kimya Problemleri - Chemical Problems. 2016, no. 3, pp.244-270. (In Azerbaijan).

\title{
SOME FEATURES OF ALKYLATION REACTION OF PHENOL WITH DIMERIZATION PRODUCTS OF C 4-FRACTION OF PYROLYSIS PROCESS
}

\author{
V.H.Mirzoyev
}

Y.Mamedaliyev Institute of Petrochemical Processes, ANAS

Khojali Ave.30, Baku AZ 1025, Azerbaijan Republic; e-mail: Tural110 @mail.ru

\begin{abstract}
Alkylation reaction of phenol has been analysed in the presence of KU-23 catalyst by means of C4fraction dimerization products (after isolation of divinyl) obtained in the course of pyrolysis of lowoctane benzine. Alkylation reactions have been performed on a facility of periodic operation. Alkylation reaction made it possible to reveal an effect of temperature, molar correlation of primary components, time of reaction and quantity of catalyst per yield and selectivity of targeted product. The research went to show that in accordance with phenol alkylation reaction with products of dimerization of $\mathrm{C}_{4}$ fraction of pyrolysis process in the presence of KU-23 - temperature $120^{\circ} \mathrm{C}$, correlation of phenol to $1: 2 \mathrm{~mol}$ fraction, reaction period 5 hours and quantity of catalyst 10\% -- the yield of targeted product with respect to the phenol in question is $80.4 \%$ and selectivity $95.7 \%$.
\end{abstract}

Keywords: phenol, dimerization products of $C_{4}$-fraction, alkylation, yield, selectivity, n-alkylphenol

\section{НЕКОТОРЫЕ ОСОБЕННОСТИ РЕАКЦИИ АЛКИЛИРОВАНИЯ ФЕНОЛА ПРОДУКТАМИ ДИМЕРИЗАЦИИ $C_{4^{-}}$ФРАКЦИИ ПРОЦЕССА ПИРОЛИЗА}

\section{В.Г.Мирзоев}

Институт нефтехимических прочессов им акад.Ю.Мамедалиева

Начиональной АН Азербайджана

AZ 1025 Баку, пр.Ходжаль, 30; e-mail: Tural110@таil.ru

Исследована реакция алкилирования фенола в присутствии катализатора КУ-23 продуктами димеризации $C_{4}$-фракиии (после выделения дивинила), полученного в процессе пиролиза низкооктановых бензинов. Реакиии алкилирования осуществлялись на установке периодического действия. В результате реакции алкилирования было выявлено действие температуры, мольного соотношения первичных компонентов, время реакции и количества катализатора на выход и селективность иелевого продукта. В результате исследования было установлено, что при нижеследующих условиях реакции алкилирования фенола с продуктами димеризации проиесса пиролиза $C_{4}$ - фракции в присутствии катализатора $\mathrm{KУ}$-23: температуры $120^{\circ} \mathrm{C}$, соотнотении фенола к фракиии 1:2 моль, продолжительности реакции 5 часов и количестве катализатора $10 \%$ выход целевого продукта по отношению к взятому фенолу составляет 80.4\%, а селективность - продукту $95.7 \%$.

Ключевые слова: фенол, продукты димеризации $C_{4}$-фракции, алкилирование, выход, селективность, $n$-алкилфенол. 